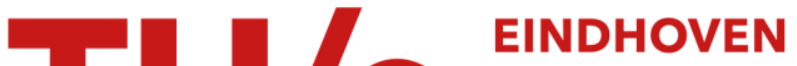 UNIVERSITY OF TECHNOLOGY
}

\section{Comparison of spherically and irregularly shaped stationary phase packings in microcolumn liquid chromatography}

Citation for published version (APA):

Vissers, J. P. C., Hoef, van den, E. C. J., Claessens, H. A., Laven, J., \& Cramers, C. A. M. G. (1995). Comparison of spherically and irregularly shaped stationary phase packings in microcolumn liquid chromatography. Journal of Microcolumn Separations, 7(3), 239-245. https://doi.org/10.1002/mcs.1220070308

DOI:

10.1002/mcs. 1220070308

Document status and date:

Published: 01/01/1995

Document Version:

Publisher's PDF, also known as Version of Record (includes final page, issue and volume numbers)

Please check the document version of this publication:

- A submitted manuscript is the version of the article upon submission and before peer-review. There can be important differences between the submitted version and the official published version of record. People interested in the research are advised to contact the author for the final version of the publication, or visit the $\mathrm{DOI}$ to the publisher's website.

- The final author version and the galley proof are versions of the publication after peer review.

- The final published version features the final layout of the paper including the volume, issue and page numbers.

Link to publication

\section{General rights}

Copyright and moral rights for the publications made accessible in the public portal are retained by the authors and/or other copyright owners and it is a condition of accessing publications that users recognise and abide by the legal requirements associated with these rights.

- Users may download and print one copy of any publication from the public portal for the purpose of private study or research.

- You may not further distribute the material or use it for any profit-making activity or commercial gain

- You may freely distribute the URL identifying the publication in the public portal.

If the publication is distributed under the terms of Article $25 \mathrm{fa}$ of the Dutch Copyright Act, indicated by the "Taverne" license above, please follow below link for the End User Agreement:

www.tue.nl/taverne

Take down policy

If you believe that this document breaches copyright please contact us at:

openaccess@tue.nl

providing details and we will investigate your claim. 


\title{
Comparison of Spherically and Irregularly Shaped Stationary Phase Packings in Microcolumn Liquid Chromatography
}

\author{
Johannes P.C. Vissers, ${ }^{*, \neq}$ Edgar C.J. van den Hoef, ${ }^{*}$ Henk A. Claessens, ${ }^{*}$ \\ Jozua Laven, ${ }^{\dagger}$ and Carel A. Cramers* \\ *Laboratory of Instrumental Analysis and ${ }^{\dagger}$ Laboratory of Colloid Chemistry, Eindhoven \\ University of Technology, P.O. Box 513, 5600 MB Eindhoven, the Netherlands
}

\begin{abstract}
Spherically and irregularly shaped reversed phase packings were used to slurry pack capillary fused silica columns. The selection of the packing solvents was based on the colloidal properties of the stationary phase particles and investigated by sedimentation experiments. The chromatographic performance of the microcolumns was measured with conventional parameters from plate and rate theories, and the column resistance parameter and separation impedance. Also studied was the time of analysis. The performance of spherical and irregular packings was comparable with a light preference for spherically shaped materials when time of analysis is concerned. (c) $1995 \mathrm{John}$ Wiley \& Sons, Inc.
\end{abstract}

Key words: microcolumn liquid chromatography, spherically and irregularly shaped particles, slurry packing, efficiency optimization

\section{INTRODUCTION}

Spherically shaped stationary phase particles are generally believed to have better chromatographic properties, i.e., a higher number of plates and a better column life expectancy, than their irregularly shaped counter parts. This was especially the case after the introduction of spherical silica gels as support for stationary phases in liquid chromatographic (LC) columns $[1,2]$. Later studies showed, however, that no or limited advantages arise from the use of spherically shaped particles as compared to irregularly shaped particles [3-9]. In order to compare packing materials with different particle shaped, and their use in LC, the particle geometry has to be characterized and the packing method optimized for each type of stationary phase individually. Most comparative studies on the performance of spherical and irregular silicas lack of proper particle characterization, resulting in incorrect conclusions when reduced parameters, like reduced plate height $h$, separation impedance $E$, and $K n o x$-plots are used.

In microcolumn LC, spherical stationary phases are almost exclusively used. Exceptions are the work of McGuffin and Novotny [9], who did pioneering work on the optimization and evaluation of packed capillary columns using spherically and irregularly shaped materials, and the work of Wilson et al. [10], who studied the effect of the column to particle diameter for both irregular and spherically packings. Both studies $[9,10]$ involved normal phase chromatography. A detailed comparison on the use of spherically and irregularly shaped particles in microcolumn LC has, by the knowledge of the authors, not been done yet. Furthermore, slurry packing optimization in microcolumn LC has only been performed on spherical packing materials.

This paper reports how the packing of fused silica capillaries can easily be optimized using proper packing solvents. Furthermore it is demonstrated whether the shape of the particles influences the LC performance. This study employs reversed phase chromatography to determine microcolumn efficiencies. Columns are compared by the number of plates per unit of length $N / L$, the plate height $H_{\min }$ at optimum linear mobile phase velocity, the reduced plate

\footnotetext{
₹o whom correspondence should be addressed at LC Packings, Baarsjesweg 154, 1057 HM Amsterdam, the Netherlands
} 
height $h_{\min }$ at optimum reduced mobile phase velocity, the flow resistance parameter $\Phi$, the separation impedance $E$, and the time of analysis.

\section{EXPERIMENTAL}

In this study only reversed phase particles were used. The packing material particles were suspended at a concentration of $100 \mathrm{~kg} \cdot \mathrm{m}^{-3}$ in a range of slurry liquids by sonication for 10 min. Thereafter the slurry was transferred to the slurry reservoir with a syringe. Acetone and methanol $(\mathrm{MeOH})$ were purchased from Merck (Darmstadt, Germany). Acetonitrile (ACN) was from Janssen Chimica (Beerse, Belgium), uracil, anthracene, naphthalene, and phenanthrene from Fluka AG (Buchs, Switzerland) and tetrahydrofurane (THF) from Biosolve LTD (Barneveld, the Netherlands). All chemicals were of p.a. grade. Water was purified and demineralized with a Milli-Q water purification system (Waters-Millipore, Milford, MA, USA) prior to use.

Basically, the same silicas with the same bonding chemistry should be used when spherical particles are to be compared with irregulars. This is not achievable practically, however, since different kinds of chemistry are involved in the production of, respectively, spherically and irregularly shaped silica sols, resulting in chemically different species. Therefore, spherically and irregularly shaped reversed phase packing materials were purchased from two different manufacturers. The materials per manufacturer had the same bonding chemistry. Nucleosil 100$5 \mathrm{C} 18$ and Polygosil 100-5 C18 were obtained from Machery-Nagel GmbH \& Co KG (Düren, Germany). BioSil C18 HL 90-5 S and BioSil C18 HL 90-5 were obtained from BioRad RSL nv. (Nazareth, Belgium).

The particle settling device, the construction of the fused silica capillary columns, and the packing equipment are described in a previous paper [11]. The mean particle diameters (median) of the spherically shaped stationary phases were determined by means of light scattering techniques [11]. The average particle size of Nucleosil 100-5 C18 and BioSil C18 HL 90-5 $\mathrm{S}$, both spherically shaped, was 5.10 and 5.70 $\mu \mathrm{m}$, respectively. The irregularly shaped packings were characterized by their projected area diameter $[11,12]$. The mean projected area diameter of the particles of Polygosil 100-5 C18 and BioSil C18 HL 90-5, both irregularly shaped, were 6.33 and $6.57 \mu \mathrm{m}$, respectively. Nucleosil 100-5 C18 and Polygosil 100-5 C18 were packed at a pressure of 500 bar, and BioSil C18 HL 90-5 S and BioSil C18 HL 90-5 were packed at a pressure of $300 \mathrm{bar}$.

The HPLC system consisted of a Phoenix $20 \mathrm{CU}$ syringe pump and a Phoenix 20 syringe slave pump (Carlo Erba Instruments, Milan, Italy), a 785A Programmable Absorbance detector (Applied Biosystems, San Jose, CA, USA) equipped with a $z$-shaped detection cell (LCPackings, Amsterdam, the Netherlands), and a $60 \mathrm{nl} \mathrm{CI4W} \mathrm{injection} \mathrm{valve} \mathrm{(VICI-AG} \mathrm{Valco}$ Europe, Schenkon, Switzerland). A 0.2- $\mu \mathrm{m}$ nylon membrane (Alltech Associates Inc., Deerfield, IL, USA) was positioned into the valve outlet to the column in order to prevent that stationary phase particles could enter the injection valve. UV detection was performed at 254 or $275 \mathrm{~nm}$. The output of the detector and the pressure of the pump were monitored with a BD41 potentiometric recorder (Kipp \& Zonen, Delft, the Netherlands). Data handling was performed with Nelson 5.2 software (Perkin-Elmer Nelson, Cupertine, CA, USA).

The reversed phase columns were evaluated isocratically with a test-mixture containing four components: uracil (deal volume marker), naphthalene, phenanthrene, and anthracene. The concentration of all components was approximately $0.1 \mathrm{~mol} \cdot \mathrm{m}^{-3}$. As the mobile phase acetonitrile/water 70:30 (v/v) was used. The individual solvents of the mobile phase were filtered through a $0.45-\mu \mathrm{m}$ filter. Prior to use, the mobile phase was degassed with helium. The peak of naphthalene or phenanthrene was used to calculate column efficiencies. Plate heights were calculated using an algorithm developed by Foley and Dorsey [13]. The diffusion coefficients $D_{m}$ of the test compounds in the mobile phase were calculated as proposed by Wilke and Chang [16].

\section{RESULTS AND DISCUSSION}

In order to obtain efficient, reproducible packed fused silica capillary columns, the stationary phase particles preferably should have coagulating properties in the packing liquid [11]. However, instead of kinetic settling experiments, involving very detailed particle characterization, the coagulating properties of packing liquids can also be determined by means of the final height of the sediment, i.e., the height of the sediment after the particles are completely 
settled [14,15]. A high sediment is found with coagulated particles, a low sediment in the case of noncoagulated particles.

In Figure 1 the final height of the sediments of four reversed phase packing materials, two spherically and two irregularly shaped, is given in four different kind of liquids. A good example is Nucleosil 100-5 C18, which is coagulated much more severe in $\mathrm{ACN} / \mathrm{H}_{2} \mathrm{O}$ 70:30 (v/v) than in THF. These results give, however, only relative information. To what extent the particles are coagulated, or if the particles are not coagulated at all, cannot be derived from these kind of experiments. Coagulation of the stationary phase particles in the slurry liquid is less critical [11]. For Nucleosil 100-5 C18, Polygosil 100-5 C18, and BioSil C18 HL 90-5, the mixture $\mathrm{ACN} / \mathrm{H}_{2} \mathrm{O} 70: 30(\mathrm{v} / \mathrm{v})$ was used as the packing liquid. For BioSil C18 HL 90-5 S this was $\mathrm{ACN} / \mathrm{H}_{2} \mathrm{O} 70: 30(\mathrm{w} / \mathrm{w})$. As slurry liquid acetone was used, because of its low viscosity (increased packing speed) and relatively low toxicity, for all stationary phases.

Van Deemter ( $H$ vs. $u$ ) and Knox ( $h$ vs. $\nu$ ) curves for all stationary phase for a retained compound with a retention factor of ca. 3.5-4 were measured and are given in Figure 2(a) and (b). All Van Deemter curves show, as expected, very small increments in plate height with increasing mobile phase velocity. Based on the $H-u$ plots, the spherical particle stationary phases would be interpreted as the "best" column packing materials, i.e., lowest plate num-

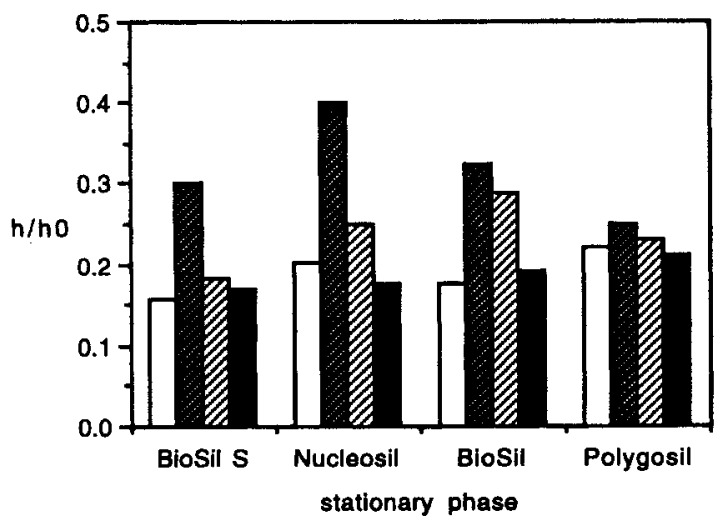

Figure 1. Normalized height, i.e., height of sediment over height of slurry, for spherically and irregularly shaped particles in a number of selected liquids. (口) acetone, (口) $\mathrm{ACN} / \mathrm{H}_{2} \mathrm{O}$, (口) $\mathrm{MeOH}$, and (ם) THF. The ratio $\mathrm{ACN} / \mathrm{H}_{2} \mathrm{O}$ was 70:30 (v/v) in all cases, BioSil C18 HL 90-5 $S$ excepted $(70: 30(w / w))$.

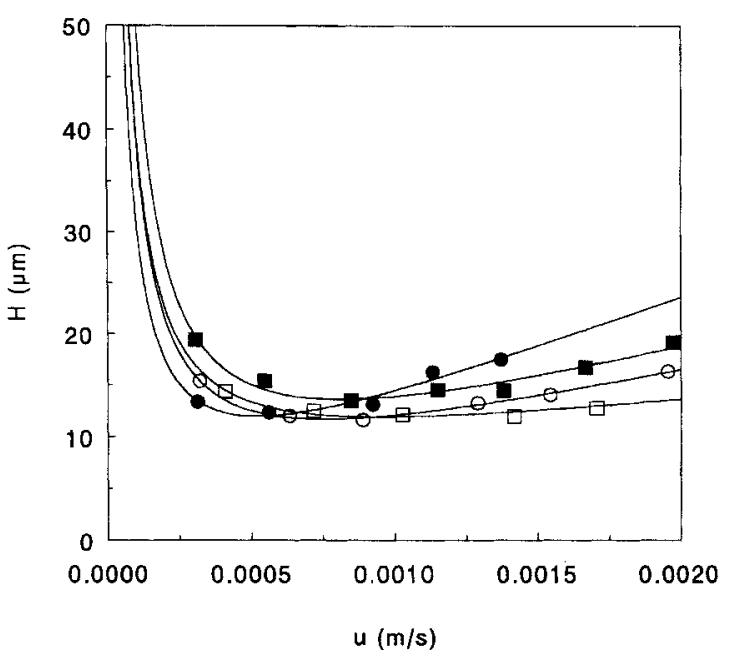

(a)

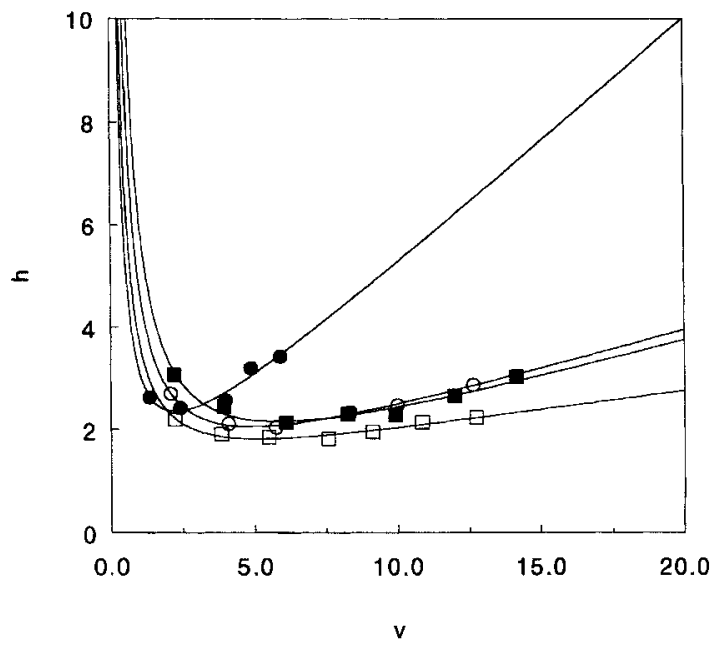

(b)

Figure 2. (a) Van Deemter curves for spherically and irregularly shaped particles. (O) BioSil C18 HL 90-5 S, (О) Nucleosil 100-5 C18, ( ) BioSil C18 HL 90-5, and ( $)$ Polygosil 100-5 C18. See the text for conditions. (b) Knox curves for spherically and irregularly shaped particles. (O) BioSil C18 HL 90-5 S, (О) Nucleosil 100-5 C18, (口) BioSil C18 HL 90-5, and (ם) Polygosil 100-5 C18, See the text for conditions.

ber at optimum mobile phase velocity. However, taking into account the repeatability of the packing process, which is ca. 5-6\%, all the $H-u$ curves should be the same. Efficiencies obtained on spherically and irregularly shaped materials, as measured by the plate height, are therefore the same too.

The differences in the minimal reduced plate height $h_{\min }$ between the spherical and 
irregular materials are somewhat larger than in the Van Deemter curves. As already mentioned in the experimental section, the irregular materials have a larger particle diameter, and are the reason why they do somewhat better in the $h-\nu$ curves. These results are confirmed by the date given in Table I, discussed in the next section.

Other useful column characteristics are the flow resistance factor $\Phi$ and the separation impedance $E$, both dimensionless parameters [17]. $\Phi$ reflects how much pressure is needed for an analysis, or which column length may be used at a given pressure and mobile phase velocity. For packed microcolumns $\Phi$ is between 500 and 1000. $E$ includes the obtained number of plates and the time and pressure needed for a separation. Its lowest expected value is 2000 . The flow resistance factor and the separation impedance for all investigated stationary phases are given in Table I. With all packing materials and packing conditions, three columns were packed and tested. The number of plates per meter $\mathrm{N} / \mathrm{m}$, the minimal plate height $H_{m i n}$, the minimal reduced plate height hmin, the total column porosity $\epsilon_{t}$, and the column permeability $K_{0}$ are given in Table I too.

Table I indicates once more the minor differences in the number of plates and the plate height Hmin that were obtained with spherical and irregular packing materials. The differences in $h_{\min }$ are, however, significant and show that the irregulars are packed more efficiently. Almost all $\Phi$-values fall in the range 500-1000, but are all at the high end, Nucleosil 100-5 C18 excepted, compared to conventional $4.6 \mathrm{~mm}$ i.d. stainless-steel columns. However, neither the spherically nor the irregularly shaped particles showed a pronounced better flow resistance parameter. Thus their resulting separation impedance values are also all of the same magnitude. Table I also indicates the minor differ- ences in number of plates that as obtained with spherically and irregularly shaped particles. The permeability of the columns was found to be somewhat higher than reported by others [18].

The performance of packed microcolumns can also be compared with respect to the speed of analysis. The time $t_{r}$ required to generate a certain number of plates is given by:

$$
t_{r}=N \frac{h}{\nu} \frac{d_{p}^{2}}{D_{m}}(1+k)
$$

where $\nu$ is the reduced mobile phase velocity, $d_{p}$ the particle diameter, and $k$ the retention factor. Naphthalene was, as a retained solute, used as the test compound to compare the times required to generate, for example, 100,000 plates on the different types of stationary phase packings. The results from the calculations are listed in Table II. The $h / \nu$ dependence of naphthalene was experimentally determined. Besides the retention time, also the column length, pressure drop and $H / u$ are given in Table II.

At first sight, the results seem to be very similar for both kind of packings. This is true as far as the column length and pressure drop are concerned. Nucleosil 100-5 C18 and Polygosil 60-5 $\mathrm{C} 18$ yield shorter analysis times compared to BioSil HL C18 90-5 S and BioSil C18 HL $90-5$, which is caused by the higher carbonloading of the BioSil materials. Comparing the spherical and irregular stationary phases per manufacturer, it can be concluded that faster analysis times can be achieved on spherical packings. Nucleosil $100-5$ C18 provides 1.07 quicker analysis times as compared to Polygosil 100-5 C18 for naphthalene at optimum reduced mobile phase velocity. For BioSil C18 HL 90-5 S compared to BioSil C18 HL 90-5 this value is 1.57. Furthermore, the BioSil materials show

Table I. Comparison of column efficiencies of different stationary phases (spherically and irregularly shaped particles; $n=3$ ).

\begin{tabular}{lccccccc}
\hline Stationary phase & $\mathrm{N} / \mathrm{m}$ & $\mathrm{H}_{\min }(\mu \mathrm{m})$ & $\mathrm{h}_{\min }$ & $\varepsilon_{\mathrm{t}}$ & $\mathrm{K}_{0}\left[10^{14} \mathrm{~m}^{2}\right]$ & $\Phi$ & $\mathrm{E}$ \\
\hline Spherically shaped & & & & & & & \\
BioSil C18 HL 90-5 S & 77800 & 13.0 & 2.54 & 0.68 & 3.21 & 830 & 5330 \\
Nucleosil 100-5 C18 & 69500 & 14.8 & 2.59 & 0.56 & 5.20 & 630 & 4420 \\
& & & & & & & \\
Irregularly shaped & & & & & & \\
BioSil C18 HL 90-5 & 77100 & 13.1 & 2.00 & 0.57 & 4.01 & 1080 & 4330 \\
Polygosil 100-5 C18 & 71800 & 13.3 & 1.94 & 0.76 & 4.67 & 860 & 3260 \\
\hline
\end{tabular}


Table II. Retention time $t_{r}$, column length $L$, and pressure drop $\Delta p$ required to generate 100,000 plates for a retained compound for columns packed with spherically and irregularly shaped particles.

\begin{tabular}{|c|c|c|c|c|}
\hline$\nu / \nu_{\mathrm{opt}}$ & $\mathrm{t}_{\mathrm{r}}(\min )$. & $L(m)$ & $\Delta p($ bar $)$ & $\mathrm{H} / \mathrm{u}(\mathrm{s})$ \\
\hline \multicolumn{5}{|l|}{ BioSil C18 HL 90-5 S } \\
\hline 0.25 & 1171 & 2.93 & 69 & 0.229 \\
\hline 0.5 & 531 & 1.76 & 83 & 0.069 \\
\hline 1 & 215 & 1.42 & 135 & 0.028 \\
\hline 2 & 132 & 1.76 & 332 & 0.017 \\
\hline 5 & 106 & 3.52 & 1660 & 0.013 \\
\hline \multicolumn{5}{|l|}{ Nucleosil 100-5 C18 } \\
\hline 0.25 & 562 & 1.69 & 62 & 0.080 \\
\hline 0.5 & 185 & 1.11 & 81 & 0.026 \\
\hline 1 & 79 & 0.95 & 139 & 0.011 \\
\hline 2 & 46 & 1.10 & 322 & 0.007 \\
\hline 5 & 30 & 1.83 & 1345 & 0.004 \\
\hline \multicolumn{5}{|l|}{ BioSil C18 HL 90-5 } \\
\hline 0.25 & 2831 & 3.74 & 66 & 0.361 \\
\hline 0.5 & 838 & 2.21 & 79 & 0.107 \\
\hline 1 & 337 & 1.78 & 126 & 0.043 \\
\hline 2 & 209 & 2.22 & 314 & 0.027 \\
\hline 5 & 171 & 4.54 & 1609 & 0.022 \\
\hline \multicolumn{5}{|l|}{ Polygosil 100-5 C18 } \\
\hline 0.25 & 661 & 2.26 & 60 & 0.131 \\
\hline 0.5 & 204 & 1.39 & 75 & 0.040 \\
\hline 1 & 84 & 1.15 & 123 & 0.017 \\
\hline 2 & 51 & 1.39 & 297 & 0.010 \\
\hline 5 & 38 & 2.63 & 1404 & 0.008 \\
\hline
\end{tabular}

less favorable $H / u$ values than Nucleosil $100-5$ C18 and Polygosil 100-5 C18 for naphthalene. The results in Table II show clearly why microcolumns in LC are operated near the optimum reduced mobile phase velocity. To achieve an acceptable number of plates at two or five times the optimum velocity of the mobile phase already results in undesired inlet pressures. At five times the optimum rate of the mobile phase the inlet pressure exceeds the pressure limit of all LC pumps applied at present.

To show the potential of microcolumn LC, a polycarbonate sample, after microwave extraction, was separated by gradient analysis on a $0.40 \mathrm{~m} \times 320 \mu \mathrm{m}$ i.d. fused silica capillary column packed with BioSil C18 HL 90-5 S. The chromatogram is given in Figure 3. The mobile phase consisted of $\mathrm{ACN} / \mathrm{H}_{2} \mathrm{O} 65: 35(\mathrm{v} / \mathrm{v})$ and was programmed to $\mathrm{ACN} / \mathrm{H}_{2} \mathrm{O} 95: 5(\mathrm{v} / \mathrm{v})$ in $15 \mathrm{~min}$. In an additional $15 \mathrm{~min}$ the mobile phase was programmed to $100 \% \mathrm{ACN}$ and was kept constant for $30 \mathrm{~min}$. The rate of the mobile phase was $5 \mu \mathrm{L} \cdot \min ^{-1}$. UV absorbance detection was performed at $264 \mathrm{~nm}$.
As another example, the efficient separation of a polymer-additives sample is demonstrated in Figure 4. This chromatogram was obtained on a $0.40 \mathrm{~m} \times 320 \mu \mathrm{m}$ i.d. microcolumn packed with Polygosil 100-5 C18. The mobile phase consisted of $\mathrm{ACN} / \mathrm{CHCl}_{3} 95: 5(\mathrm{v} / \mathrm{v})$ and the rate of the mobile phase was $10 \mu \mathrm{l}$. $\min ^{-1}$. Detection was carried out at $254 \mathrm{~nm}$. The second example, especially shows a very good performance, as regarding the excellent resolution at short retention times.

\section{CONCLUSIONS}

Good, efficiently packed microcolumns for LC can be obtained with spherically as well as irregularly shaped particles. The proper packing solvents can easily be selected by means of sedimentation experiments. Suspension liquids in which the particles are coagulated are to be preferred as the packing liquid. The selection of the slurry liquid is not determined by the coagulating properties of the stationary phase particles in the slurry liquid. Particles have to 
be characterized properly by size if reduced parameters are to be used as optimization criteria. Based on the obtained results, no distinction can be made on whether spherically or irregularly shaped packing material particles give the best chromatographic performance.
Considering the time of analysis the spherical packings appear slightly to be preferred over the irregularly shaped packings. Maybe the main advantage of irregulars is their low cost compared to spherical particles. On the other hand, spherical particles are believed to be better



Figure 3. Microcolumn LC separation of a microwave extract of a polycarbonate sample on a BioSil $\left.\mathrm{C18} \mathrm{HL} \mathrm{90-5} \mathrm{S} \mathrm{column.} \mathrm{The} \mathrm{mobile} \mathrm{phase} \mathrm{consisted} \mathrm{initially} \mathrm{of} \mathrm{ACN} / \mathrm{H}_{2} \mathrm{O} 65: 35 \mathrm{v} / \mathrm{v}\right)$. The amount of $A C N$ was increased up to $95 \%(v / v)$ in $15 \mathrm{~min}$. In an additional 15 min the amount of $A C N$ was programmed to $100 \%$ and was kept constant for $30 \mathrm{~min}$. The length of the column was $0.40 \mathrm{~m}$ and the i.d. $320 \mu \mathrm{m}$. The flow rate was $5 \mu \mathrm{l} \cdot \mathrm{min}^{-1}$. UV-absorption detection was performed at $264 \mathrm{~nm}$.

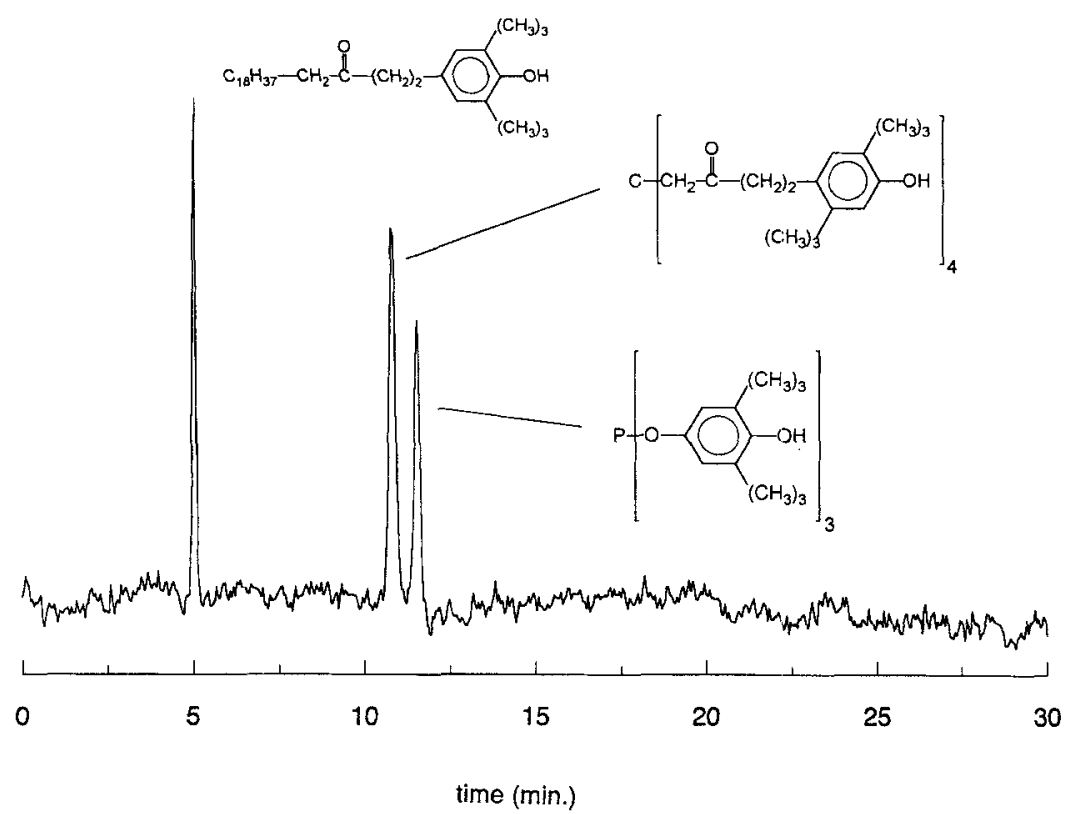

Figure 4. Microcolumn LC analysis of polymer additives on a Polygosil 100-5 C18 column. The mobile phase consisted of $\mathrm{ACN} / \mathrm{CHCl}_{3} 95: 5(\mathrm{v} / \mathrm{v})$ and the flow rate was $10 \mu \mathrm{l} \cdot \mathrm{min}^{-1}$. The column length was $0.40 \mathrm{~m}$ and the i.d. $320 \mu \mathrm{m}$. UV-absorption detection was performed at $254 \mathrm{~nm}$. 
pressure resistant than irregularly shaped particles.

\section{ACKNOWLEDGMENTS}

The authors would like to express their gratitude to C. Dewaele (BioRad RSL nv., Nazareth, Belgium) for providing the BioSil C18 HL 90-5 S stationary phase. They also want to thank M.J.J. Hetem (General Electric Plastics, Bergen op Zoom, the Netherlands) for putting the industrial samples (polycarbonate and polymer additives) and a gradient system at their disposal.

\section{REFERENCES}

[1] J. Asshauer and I. Halász, J. Chromatogr. Sci. 12, 139 (1974).

[2] J.J. Kirkland, J. Chromatogr. Sci. 10, 593 (1972).

[3] G.R. Laird, J. Jurand, and J.H. Knox, Proc. Soc. Anal. Chem. 11, 311 (1974).

[4] K.K. Unger, W. Messner, and K.F. Krebs, J. Chromatogr. 149, (1978) 1.

[5] K.K. Unger, in Porous Silica (Elsevier, Amsterdam, the Netherlands, 1979), p. 184.

[6] R. Ohmacht and I. Halász, Chromatographia, 14, 216 (1981).

[7] M. Verzele, J. van Dijck, P. Mussche, and C. Dewaele, J. Liq. Chromatogr. 5, 31 (1982).
[8] M. Verzele, C. Dewaele, and D. Duquet, $J$. Chromatogr. 39, 111 (1987).

[9] V.L. McGuffin and M. Novotny, J. Chromatogr. 255, 381 (1983).

[10] W.H. Wilson, H.M. McNair, Y.F. Maa, and K.J. Hyver, J. High Resol. Chromatogr. 13, 18 (1990).

[11] J.P.C. Vissers, H.A. Claessens, J. Laven, and C.A. Cramers, Anal. Chem., accepted for publication.

[12] R. Clift, J.R. Grace, and M.E. Weber, in Bubbles, Drops and Particles (Academic, London, England, 1978), p. 16.

[13] J.P. Foley and J.G. Dorsey, Anal. Chem. 55, 730 (1983).

[14] D.C. Shelly and T.J. Edkins, J. Chromatogr. 411, 185 (1987).

[15] H. Wang, R.A. Hartwick, N.T. Miller, and D.C. Shelly, J. Chromatogr. 523, 23 (1990).

[16] C.R. Wilke and P. Chang, AIChE. J. 1, 261 (1955).

[17] P.A. Bristow and J.H. Knox, Chromatographia 1, 279 (1977).

[18] J.C. Gluckman, A. Hirose, V.L. McGuffin, and M. Novotny, Chromatographia 17, 6 (1983).

Received: February 1, 1995 Accepted: May 15, 1995 